\section{Self, Philosophical Considerations}

Şerife Tekin

Daemen College, U.S.A.

From Socrates' admonition to know oneself and his claim that the unexamined life is not worth living, the self has occupied a central place in philosophical and scientific inquiry. Debates about the self include metaphysical questions on the nature and reality of selfhood, empirical questions about the developmental and historical trajectory of the human selves, and ethical questions about agency, responsibility, and autonomy. The answers to these metaphysical, empirical, and ethical questions are intertwined, as the nature of selfhood both constrains and enables the range of moral and political actions the individual engages with in a social world. This entry focuses on the realist and antirealist positions on the metaphysical question of the reality of the self and its scientific investigation. Realism has two fundamental commitments about the world posited by scientific theories: existence and evaluation-independence. According to the existence claim, both the everyday world of objects and their properties-the subject of scientific theorizing-do exist. According to the evaluation-independence claim, the objects and properties posited by a scientific theory exist independent from what human beings think about them or how they are linguistically articulated. As a corollary, realists about the self argue that the self exists; its features are evaluation independent; and these features can be scientifically investigated. Antirealists on the other hand suggest that there is no such thing as the self, that it is merely a construct and what is identified as its features are contingent upon cultural and linguistic practices.
The Cartesian notion of the self sets the stage for both the realist and the antirealist approaches. In Meditations, Descartes seeks to investigate the grounds for his beliefs about the world. He explores whether any of his ordinary beliefs could survive methodical doubt. He goes so far as to doubt the existence of the external world itself by positing that an evil demon could make humans perceive the external world even if one did not exist. In this process, the only thing that Descartes cannot doubt is the fact that he is thinking. Thus, the very activity of thinking (i.e., doubting) is evidence of his own existence: "I must finally conclude that the proposition, I am, I exist, is necessarily true whenever it is put forward by me or conceived in my mind" (Descartes, 1641/1968).

Descartes concludes that he knows one thing with certainty, the existence of a thinking substance, his "self." According to Descartes reality is made up of two fundamental kinds of substance: mental and material. Human beings, as parts of reality, are constituted by the mental, which has no extension in space, and the material, which is extended but is void of thoughts. Descartes' dualism about substances has given rise to the famous mind-body problem, one of the most important topics in philosophy of mind. Descartes constrains selfhood to immaterial substance only. The self is a thinking "thing," or metaphysically simple, unified, bounded, determinate, permanent, independent, and self-transparent substance (Descartes, 1641/1968). The Cartesian view of mind then allows us to specify what makes a person the same person over time: it is not the body; it is the possession of the immutable thing that constitutes the self. This mental substance makes the self the same unchanging entity from birth to death and possibly beyond. To summarize, for Descartes the self exists as a nonphysical and evaluation-independent entity; that is, it is there even if no one knows 
about it. Because it is compatible with most theologies that postulate souls existing in an independent "realm" of existence distinct from that of the physical world, and also because it resonates with common sense, Descartes's view has dominated modern European philosophy.

Most of the realist and the antirealist views on the self have been developed in reference to the Cartesian self. Antirealists deny the existence of the self by arguing that there is no such thing as the self. Rather the self is an illusion, a fiction of the mind. There would not be such a thing that we call the self if there was no one to perceive it. They further deny the evaluation-independence claim, arguing that the concept of the self is invented by cultural, social, and linguistic conventions, and it is nothing but a useful conceptual tool for organizing human experience. Unlike what a Cartesian claims, there is no substance such as the self, the self is not a determinate, timeless, unified, and bounded thing. In fact, for the antirealists, this malleable nature of the self is evidence that the self cannot be a evaluation-independent and real thing in the way that chemical elements such as gold are (e.g., Dennett, 1991; Foucault, 1979; Rorty, 1989).

Contemporary realists argue that there is such a thing as the self (the self exists) and it is evaluation-independent. Selves would exist even if even if our social, cultural, and linguistic conventions did not, but that they would be more impoverished than they currently are. However, most realists also deny the Cartesian view of the self as an immutable and unchanging thing from birth to death.

Realism about the self comes in different varieties. While some realists defend the existence of the self by committing themselves to the existence of a substance-whether material or immaterial-others take issue with Cartesian commitment to substance. Instead they observe the phenomenological experience of the self and pay attention to the empirical evidence drawn from cognitive sciences and neuroscience. They relax the Cartesian limitations on the self as permanent, stable, and nonchanging, but still construe it as real (e.g., Flanagan, 1991; Jopling, 1997; Neisser, 1988). There are also some realists who claim that the self is real but remain agnostic about its nature (Graham, 2000; Kennedy \& Graham, 2006). Further, some construe antirealism as a reaction to the Cartesian account of the self; once we abandon the Cartesian definition of the self, antirealism will no longer be a viable view (Graham, 2000; Jopling, 1997; Kennedy \& Graham, 2006).

Antirealists are represented by a number of continental philosophers with postmodern leanings, for example Richard Rorty and Michel Foucault, and a number of contemporary analytic philosophers, for example Daniel Dennett. Realists include psychologists and empirically informed philosophers of mind including William James, Owen Flanagan, Ulric Neisser, and George Graham.

\section{Varieties of Antirealism about the Self}

Postmodern philosophers are opposed to the Cartesian account of the self as a unified, permanent, evaluation-independent substance that is impervious to perturbations and changes. In their view, the self is construct that can be shaped in as many diverse ways as is socially, culturally, and linguistically possible. Unlike the Cartesian assumption, there are no a priori limits on the ways in which selves can be created and recreated, because there is no singular determinate self to begin with. When it comes to the self, there are no facts. This view is summarized in such propositions as "there is no such thing as the self," "the self is an illusion," and "there is no thinking, experiencing subject” (Kennedy \& Graham, 2006).

The phenomenal experience of having a self-that is, feelings of agency and intentionality, acting according to beliefs and desires, and being embedded in and interacting with a physical and social environment-provide apparent evidence of the existence of the self. However, for antirealists, such phenomenal information is not objectively grounded; rather, 
it shows variation across subjects. Because it is impoverished, such information is usually enriched or crafted by metaphors, narratives, and symbols.

Michel Foucault argues that the self is not a hidden metaphysical substance that can be unearthed, but has developed historically as a correlate of cultural and social institutions (Foucault, 1979). This means, for instance, that the concept of the self had different connotations in Ancient Greek society from its connotations in contemporary society. Thus, what people consider as the self is not a fixed, unchanging thing, as Descartes postulated it, but an evolving concept dependent on cultural and social practices and relationships.

Similar to Foucault, Richard Rorty argues that there is no unchanging metaphysical substance such as the self. While Foucault emphasized the idea that the self is a product of society and culture, Rorty also considers it to be a product of linguistic practices (Rorty, 1989). Just as an author or a poet creates a novel or poem from scratch, a person creates and transforms herself through the stories (or narratives) she tells to herself about herself at particular times in particular situations. Thus, just like a novel or a poem, the self is a contingent phenomenon; it is dependent on the subject's perceptions and evaluations of herself. For Rorty, this makes the realist claim that the self is a timeless, fixed unity, wrong.

A contemporary philosopher of mind and cognitive science, Daniel Dennett also defends the antirealist view of the self also by appealing to the stories or narratives we tell about ourselves. Unlike Rorty, however, Dennett is interested in psychology and cognitive sciences, rather than the activity of novelists or poets. Dennett vocalizes the two antirealist commitments and argues that the self does not exist as a concrete thing, nor as a metaphysical substance, and that what is considered as the self is not evaluation-independent (Dennett, 1991). Each "normal" individual of the species Homo sapiens, for Dennett, creates a self by spinning stories about herself in the process of presenting herself to others through language.
The tendency to create selves by way of creating stories, for humans, is akin to how spiders weave webs to protect themselves; it is both intrinsic and unconscious (Dennett, 1991).

Because it is constructed and abstracted out of narratives, the self is permeable and flexible. Dennett uses multiple personality disorder to illustrate his ideas (Dennett \& Humphrey, 1989; see also Graham, 2000 for a detailed discussion). For Dennett the multiple personalities claimed to be possessed by the same body are difficult to individuate, both by the individual and others, because the self is not a real thing that is easily identifiable.

\section{Varieties of Realism about the Self}

Realists object to the antirealist claim that the self is not a real thing but fiction, a product of the social, cultural, and linguistic conventions, for three reasons. First, they assert that phenomenal experience of selfhood (conscious experience) manifests a physically embodied and socially embedded configuration; as a result, empirical research in the sciences of the mind provides robust reasons to deny antirealism. Second, they argue that those antirealists who argue that the self is a fiction because the evidence for the reality of the self is subjectively variant are confusing self-concepts (how the self represents itself to itself) with the self. While the linguistic representations of the self, i.e., self-concepts, are manifest in the social, cultural, and linguistic world, they are also grounded on the physical body. The embodiment and the developmental trajectory of the self provide objective and universal facts about human selves. Third, they declare that the antirealist position is based on overly stringent expectations of what the self must be in order to exist.

William James has made major contributions to a realist picture of the self that is responsive to the experience of ordinary human beings. For James, the self is constituted by four different-but complementary-selves: (a) the material self, (b) the social self, (c) the 
spiritual self, and (d) the pure ego. The material self includes the body; there is a certain kind of intimacy that each person feels toward their own body. For example, we feel our own hunger more intimately than we do the hunger of others, even though we may empathize with them. The material self also includes clothes, wealth, and immediate family. For instance, referring to the family, James writes, "when they die a part of ourselves is gone" (James, 1890/1983). The social self is constituted by the recognition that one gets from interpersonal relationships. Humans are "gregarious animals" who have an innate tendency to be noticed favorably and to seek the respect of others. The spiritual self involves moral sensibility, conscience, and the will. Finally, the pure ego is the self of selves, which mediates between the ideas of the self and its actions in the world. The self of selves can be viewed as self-consciousness because it is active whenever the individual is conscious of something; for example, when uttering a word.

William James is a realist, committed to the claim that the self is a real phenomenon, a complex language-independent entity with several constituents. His investigation of the self follows both the phenomenological method, where he uses his own experience of himself as a framework to understand the self, and the scientific method, where he uses psychopathological cases, such as multiple personality, to theorize his account. Unlike Dennett who used multiple personality to argue for an antirealist approach to the self, James uses psychopathology as evidence for the claim that there are selves.

In addition to being an important figure in the development of cognitive psychology, Ulric Neisser also helped found the ecological psychology movement. This movement was triggered by worries about the exclusive focus of the field of cognitive psychology on computer modeling and information processing. Ecological psychologists challenge cognitive psychology not to confine itself to the laboratory but to also study how actual people interact in the world outside the laboratory.
Neisser argues that the forms of information that individuate the self are so different from one another that it is plausible to suggest that each form of information establishes a different "self" (Neisser, 1988). Neisser's different selves are (a) the ecological self, or the self that perceives and who is situated in the physical world; (b) the interpersonal self, or the self embedded in the social world who develops through intersubjectivity; (c) the extended self, or the self in time that is grounded on memory of the past and anticipation about the future; (d) the private self, or the self of private experiences that are not available to others; and (e) the conceptual self, or the self that represents the self to itself by drawing on the properties of the self and the social, cultural, and linguistic context to which it belongs. Even though these selves specified by five different kinds of information are not experienced as distinct and independent, they differ in their developmental histories; for instance, the ecological and intersubjective selves start at birth, whereas the conceptual self develops with the development of language.

An empirically informed philosopher of mind and moral psychologist, Owen Flanagan is also a proponent of realism about the self. He carves the self into what he calls the "actual full identity" and "self-represented identity," hoping to account for the self from both an objective point of view (via a complete science of mind, behavior, and personality) and a subjective point of view (via subject's self-reports at a given time and place). Actual full identity is a dynamic integrated system of individual's past and present identifications, desires, commitments, aspirations, beliefs, dispositions, temperaments, roles, acts, and actional patterns, as well as her self-understandings (even the incorrect ones) (Flanagan, 1991). Self-represented identity is a collection of various representations of actual full identity. Self-representations, in this sense, never have direct access to actual full identity; they can only approximate it with varying degrees of success. 
Committed to realist intuitions, Flanagan argues there is a self and it is multiplex; that is, the various self-representations are collected into a single autobiographical narrative by the subject, who performs "active authorial work" to integrate her memories about the past, plans about the future, various projects, and so on (Flanagan, 1991). Such a narrative warrants the psychological connectedness possible in a first-person perspective, thereby reiterating the person over time. Self-representations, through such autobiographical narratives, shape actual full identity in two senses.

First, when considered as a cognitive activity, representing one's self involves activating certain mental representations and cognitive structures. This activity realigns, recasts, and modifies the representations already in place. For instance, a subject representing herself as a vegan activist fighting for animal rights realigns her other self-representations, such as her participation in demonstrations, the articles she publishes in the local newspaper about the unethical treatment of animals, and so on.

Second, the self as represented has motivational bearings and behavioral effects. In this case, the subject's placement of her self-conception in motivational circuits fine tunes her actions. For instance, having represented herself as a vegan activist fighting for animal rights, she might feel motivated to change people's attitudes and campaign to get more people to read her articles. Such activities are constitutive of the subject's actual full identity (Flanagan, 1991). Note that, just like Rorty and Dennett, Flanagan draws attention to the importance of narratives and the social and cultural factors in the formation of the self; however, unlike the former two, he uses these arguments to argue for the reality of the self. In this respect, Flanagan's realism accommodates both the realist claim that there is such a thing as the self, and the antirealist attempts to explain how social, cultural, and linguistic factors are influential in shaping the self.
A contemporary philosopher of mind and cognitive science, George Graham is committed to the claim that the self is real, but is agnostic about what the self is. His realism is grounded on what he calls the manifestation thesis, whereby a subject's conscious experiences manifest themselves as modifications of her own experience. For example, when we become conscious of an experience such as seeing a flower, we perceive that experience as ours, not as someone else's seeing of a flower. Such selfconsciousness reveals to us that there is a self, but it does not reveal whether the self is a material or immaterial phenomenon.

In Graham's view, antirealists who question the existence of the self overestimate what we know about the self; they mistakenly believe that being a realist commits someone to a Cartesian substance called the self, forcing them to abandon realism altogether. However, if we relax the stringent Cartesian demands on selfhood and remain agnostic about its ontology, we will find realism plausible. In addition, antirealists argue for antirealism by claiming selves are indeterminate. However, for Graham, the indeterminacy of the self does not require conceding that it is unreal. According to Graham, the theoretical temptation to use determinacy to distinguish real from unreal selves should be resisted.

He suggests that describing the ontology of self requires knowing a complete set of metaphysical truths about the self, including truths about self/brain (body) relations, the nature of consciousness and intentionality, and personal identity across time. He is skeptical that we can ever know such truths; therefore, the best strategy is to commit to the existence of selves, but remain agnostic about what they may be (Graham, 2000).

SEE ALSO: Descartes' Model of the Mind; Psychometric Validity; Social Constructionism

\section{Acknowledgments}

Thanks to Owen Flanagan, George Graham, Peter Zachar, and Kathyrn Tabb for their helpful feedback on this entry. 


\section{References}

Dennett, D. (1991). Consciousness explained. Boston, MA: Little, Brown and Company.

Dennett, D., \& Humphrey, N. (1989). Speaking for ourselves: An assessment of multiple personality disorder. Raritan, 9, 68-69.

Descartes, R. (1641/1968). Meditations on first philosophy. In E. Haldane \& G. Ross (Eds.), The philosophical works of Descartes (pp. 131-200). Cambridge, U.K.: Cambridge University Press.

Flanagan, O. (1991). Varieties of moral personality: Ethics and psychological realism. Cambridge, MA: Harvard University Press.

Foucault, M. (1979). Discipline and punish: The birth of the prison (A. Sheridan, Trans.) New York: Vintage.

Graham, G. (2000). Self-consciousness, psychopathology and realism about self, SWIF. Philosophy of mind. Retrieved from http://www. swif.uniba.it/lei/mind/texts/allen.htm

James, W. (1890/1983). The principles of psychology. Cambridge, MA: Harvard University Press. Jopling, D. A. (1997). A "self of selves". In U. Neisser \& D. A. Jopling (Eds.), The conceptual self in context (pp. 249-267). New York: Cambridge University Press.
Kennedy, R. C., \& Graham, G. (2006). Extreme self-denial. In M. Marraffa, D. De Caro, \& F. Ferretti (Eds.), Cartographies of the mind: Philosophy and psychology in intersection (pp. 227 -242). Dordrecht: Kluwer.

Neisser, U. (1988). Five kinds of self-knowledge. Philosophical Psychology, 1(1), 35-59.

Rorty, R. (1989). Contingency, irony, and solidarity. Cambridge, U.K.: Cambridge University Press.

\section{Further Reading}

Graham, G. (2000). Self-consciousness, psychopathology and realism about self, SWIF. Philosophy of mind. Retrieved from http://www. swif.uniba.it/lei/mind/texts/allen.htm

Kennedy, R. C., \& Graham, G. (2006). Extreme self-denial. In M. Marraffa, D. De Caro, \& F. Ferretti (Eds.), Cartographies of the mind: Philosophy and psychology in intersection (pp. 227-242). Dordrecht: Kluwer. 